\title{
VIEWPOINT
}

\section{In the light of preimplantation genetic diagnosis: some ethical issues in medical genetics revisited}

\author{
Marcus E Pembrey \\ Institute of Child $\mathrm{H}$ ealth, University College L ondon
}

Sometimes a new development in a field can throw new light on old issues, if only by forcing a re-examination of basic principles. The emergence of preimplantation genetic diagnosis (PGD) as a clinical service (there are now three licensed centres for PGD in London, for example) provides such an opportunity to revisit some of the key issues with respect to the goals of medical genetic services. Since genetic analysis pervades much of medicine these days, a distinction needs to be drawn between genetics in molecular medicine generally and what is specifically a medical genetic service led by clinical geneticists. (The term medical genetics is used rather than clinical genetics only to emphasise the inclusion of the whole team of genetic scientists, embryologists, counsellors and doctors who together provide the service.) The distinction I use here is a pragmatic one; if the clinician, when faced with a specific diagnosis or on receiving the result of a genetic test, feels professionally obliged to try and forewarn the patient's relatives of their genetic risk or to discuss prenatal diagnosis, then this is the province of medical genetics. 0 therwise it is not.

PGD brings together three areas of biotechnology that have each engendered their own ethical debates: in vitro fertilisation, genetic testing, and prenatal diagnosis for the purpose of selective continuation or for PGD, establishment, of a pregnancy. It is not surprising therefore that the subject engenders a lot of debate. This makes it all the more important to tease out the separate ethical issues and decide to what extent these

Correspondence: Professor M arcus Pembrey, M othercare $U$ nit of Clinical Genetics and Fetal Medicine, Institute of Child Health, 30 G uilford Street, London W C1N $1 E$ H, UK Received July 1997; revised 9 O ctober 1997; accepted 20 O ctober 1997 are part of the widely permitted (but regulated) practices of in vitro fertilisation, genetic testing and prenatal diagnosis/selective abortion, or whether there are special concerns about PGD per se.

In Britain, at least, the prospect of realising the clinical benefits of PGD to couples at risk of transmitting serious genetic disease has been an element of the debate on the regulation of IVF and human embryo research for the last decade. It was a significant factor in the passing of the H uman Fertilisation and E mbryology A ct 1990 that permits regulated research on the human embryo within the first 14 days. One of the five purposes for which a research licence may be granted by the Human Fertilisation and E mbryology A uthority is 'to develop methods for detecting the presence of gene or chromosome abnormalities in embryos before implantation'. Britain is perhaps fortunate in already having a statutory regulatory body (the $\mathrm{H}$ uman Fertilisation and $\mathrm{E}$ mbryology A uthority) when it comes to the Council of Europe Convention on $\mathrm{H}$ uman Rights and Biomedicine, which came into being in September 1996. A rticle 36 of the Convention allows those countries that already have a law in this area which permits more than the Convention does, to opt out of relevant clauses. The key clauses as regards PGD in A rticle 18 read

- where the law allows research on embryos in vitro, it shall ensure adequate protection of the embryo;

- the creation of human embryos for research purposes is prohibited.

These were debated at the Council of Europe's Third Symposium on Bioethics in Strasbourg in December 1996, but their impact on the development of PGD 
throughout Europe is still unclear and a matter of considerable debate. ${ }^{1}$

In making the case for the development of PGD, and the embryo research that must accompany it, the contribution of PGD to the services for families threatened by genetic disease needs to be set in the broader perspective of all prenatal diagnosis and the associated genetic services. The main ethical issues are fundamentally the same. I believe that reproductive confidence is one of the key measures by which to judge genetic services and it is a particularly appropriate starting point when discussing PGD.

\section{Genetic Disease and Reproductive Confidence}

O ne fundamental measure of the health of a society is reproductive confidence. This is not the place to develop the arguments for this assertion, but a few obvious points can be made. A society in which members stop reproducing is clearly doomed and there are numerous, but often complex, socio-economic reasons why couples may delay or forego having children because they are uncertain about, or fear, what the future holds. A lack of offspring-survival confidence, engendered by the knowledge that many of their children will die young, can manifest as a reluctance to limit the number of pregnancies by contraception or other means, which in turn poses different threats to that society. ${ }^{2} \mathrm{~A} t$ an individual level there are many social and biological factors that can undermine reproductive confidence. Fear of transmitting a genetic disease to one's child can have a major impact on reproductive confidence, and this can be true whether the fear is well-founded or not. It is one of the challenges of clinical genetic services (and education of the public in genetics) to reach those who genuinely need genetic services, without unduly alarming those who are at no particular genetic risk. The impact of genetic knowledge alone, in the absence of acceptable prenatal diagnosis, can greatly reduce the total number of children (healthy or otherwise) born to a couple. Indeed, before the advent of prenatal diagnosis, the impact of genetic counselling was measured in terms of couples who 'chose' not to have (further) children. ${ }^{3} \mathrm{Y}$ ou do not have to be a clinical geneticist to appreciate that this 'choice' - to not risk further pregnancies where there is a high chance of a seriously affected child - was not what the couple really wanted. It was just the lesser of two evils. M ost couples wanted healthy children, but felt it was irresponsible knowingly to risk bringing an affected child into the world to suffer and to threaten family life. The impact of the introduction of prenatal diagnosis on reproductive confidence was first documented in $\mathrm{G}$ reek Cypriot families living in B ritain who were at risk for $\beta$-thalassaemia. ${ }^{4}$ Table 1 is based on 25 couples who have passed through three phases in their reproductive life - no knowledge of the genetic risk; knowledge of the $25 \%$ chance of an affected child, but no prenatal diagnosis available; knowledge of the genetic risk and an offer of prenatal diagnosis/selective abortion. It can be seen that they virtually stopped having babies when they had the genetic knowledge alone, but increased their pregnancy rate when prenatal diagnosis became available. A similar change in reproductive behaviour occurred, at least in some families, with the introduction of early prenatal diagnosis for cystic fibrosis in $1985 .{ }^{5}$

We have to conclude that for many couples the offer of acceptable prenatal diagnosis can restore reproductive confidence to a considerable extent. However, it should be emphasised that restoration of reproductive confidence in the face of genetic risk need not depend on the availability of prenatal diagnosis alone. A ccurate carrier testing, particularly carrier exclusion, information on the prognosis of the disorder in question, the availability (and personal cost) of effective treatment or support services, and the prevailing

Table 1 The effect on reproductive confidence of $25 \mathrm{G}$ reek Cypriot couples in B ritain at risk of $\beta$-thalassaemia who experienced all three phases-(i) being unaware of genetic risks, (ii) genetic counselling alone, and (iii) genetic counselling with an offer of prenatal diagnosis

\begin{tabular}{|c|c|c|c|}
\hline & $\%$ TOP & $\begin{array}{l}\% \text { Children } \\
\text { healthy }\end{array}$ & $\begin{array}{l}\text { M arried years } \\
\text { per healthy child }\end{array}$ \\
\hline $\begin{array}{l}\text { (i) Innocent } \\
\text { (ii) R isk known, but no PND } \\
\text { (iii) R isk known, and PND available }\end{array}$ & $\begin{array}{r}0 \\
68 \\
34\end{array}$ & $\begin{array}{l}36 \\
33 \\
96\end{array}$ & $\begin{array}{r}6.6 \\
47.0 \\
4.6\end{array}$ \\
\hline
\end{tabular}

A dapted from M odell et al (1980) B M J, 280: 1347-50. 
attitude towards people with disabilities, can all influence reproductive decisions. This list serves to emphasise how central an issue reproductive confidence is in the professional sphere of the medical geneticist.

Even though availability of prenatal diagnosis permits sufficient restoration of reproductive confidence for many couples to start a pregnancy and thereby increase their prospects of a healthy child, their decision is still experienced as one of choosing the least of three evils. They still face the possibility of terminating a pregnancy for which they had such high hopes, in return for avoiding the birth of a (further) affected child or a lifetime of childlessness.

\section{The Goal of Genetic Services, Including Prenatal Diagnosis and PGD}

Reproductive confidence is very much a personal matter, but what about the impact of genetic disease on the public health, on society as a whole? What are the goals of medical genetics? The declared goals of medical genetics will tend to shape the way professionals handle clinical situations and seek to resolve difficult ethical issues that arise, so it is worth discussing these briefly before considering PGD specifically.

$U$ ntil fairly recently, a widely held view was that the goal of medical genetics was to reduce the birth prevalence of babies with, or destined to develop, genetic disease - '... The long-term aim of genetic counselling is to see that as few children as possible are born with serious genetically determined or part genetically determined handicaps. ${ }^{6}{ }^{6}$ This view is still prevalent in the public health literature on genetic screening. ${ }^{7} \mathrm{H}$ owever, such a definition sits uneasily with the desire to avoid any societal or State pressure on a woman to abort an affected fetus or remain childless. I argued $^{5}$ that a public health objective that does not accord with the aspirations of the very families it aims to help is likely to be viewed as State-inspired eugenics. I claimed that the aim should not be to reduce the birth prevalence of genetic disease, and this is also one of the conclusions of the Report of the Committee on A ssessing $G$ enetic Risks, Institute of M edicine, U SA . ${ }^{8}$ $A$ reduction in birth incidence of a genetic disorder may be the consequence of genetic counselling and prenatal diagnostic services, but it depends on what parents choose to do. This distinction between the objective and consequence of genetic services is not just playing with words. It impacts directly on how health authorities might measure the success or failure of genetic services and what outcomes are used in costbenefit analysis. If reduction in the birth prevalence of a disease is the main goal, then it is easy to slip into the nonsense of counting selective abortions for genetic disease as a 'benefit' (to the public health), when clearly any abortion is a terrible 'cost' to the woman. Modell and $\mathrm{Kuliev}^{9}$ using services for families with thalassaemia as a model, propose a general framework for economic analysis that includes non-financial costs and benefits. They point out that in the past most such analyses have been carried out to win financial support by demonstrating to health administrators that prenatal diagnosis saves money. Therefore, money has been the main unit of measurement, and non-financial costs and benefits are excluded as 'intangibles' not susceptible to objective measurement. Most publications then attempt a 'cost effectiveness' analysis, which means a comparison of the financial implications of alternative approaches to the same problem in order to identify the most efficient one. Patient treatment is viewed as an alternative to prevention by screening and prenatal diagnosis, and prevention is shown to be cheaper. In reality of course, patient treatment and the offer of prenatal diagnosis are not alternatives, but two components of the service to families at genetic disadvantage. One of the key features of their approach is that abortion of a planned/wanted pregnancy is a 'cost' never a public health 'benefit' - and the birth of a wanted child (including a chosen affected birth) is always a 'benefit'.

What then should be the overall goals of medical genetics? Pembrey and A nionwu ${ }^{10}$ have defined the aim of medical genetics as being 'to help those families with a genetic disadvantage live and reproduce as normally as possible'. This has its origins in a World $\mathrm{H}$ ealth Organization definition, ${ }^{11}$ but is considerably modified. It is the inclusion of the words 'families' and 'reproduce' in this definition that differentiates it from the aims of medicine generally. The use of the word 'families' does not, of course, preclude presymptomatic testing services for individuals concerned about their own health (where the genetic test result also has potential implications for relatives born or unborn). The very real ethical issues that stem from the fact that genetic information belongs in one sense to the family as well as the individual have been the subject of detailed analysis over the years and is not discussed 
here. PGD, on the other hand, highlights the reproduction aspect of medical genetics.

This modified W HO definition has some features that are worthy of comment. It implies that medical genetic services are concerned to restore normal biosocial function, which begs the question of what is normal. However, by expressing the goal in this way, it does allow for the fact that what is to live and reproduce normally is not a universally agreed behaviour, but can have various interpretations that are culturally dependent. Indeed, some prefer the term 'reproductive choice' to 'reproductive confidence', arguing that the latter phrase tends to disregard the fact that it can be a normal response to want to remain childless. I would argue that a true choice to remain childless is only exercised when the person is reasonably confident they could have healthy children if they so wished. The definition does assume that the aim is to lessen any social exclusion that the genetic disadvantage might engender, although the degree to which a policy of social integration should be pursued can itself be contentious (the resistance of some of the 'D eaf Community' to restoration of hearing with cochlear implants is an example). The definition also recognises a professional duty of care by starting with the phrase 'to help'.

\section{The Benefits and Disadvantages of PGD as an Additional Prenatal Diagnostic Service for Families at High Genetic Risk}

In making comparisons with other forms of prenatal diagnosis (PND), it is important to ensure that PGD is seen as an additional option for couples, not a replacement for existing prenatal diagnostic services. A S PGD becomes better established as a service, it will be important to protect the right of couples to choose other forms of PND with the offer of selective abortion, if that is their decision. PGD has, however, been an option that some couples hoped would be developed in time.

On 13 November 1986, the CIBA Foundation in London held a small workshop to consider preimplantation genetic diagnosis. In discussing the question 'Is there a clinical need?', Bernadette Modell reported that when asked to wish for whatever they would most like by way of help, a couple who had had a selective abortion for $\beta$-thalassaemia said, 'to start a pregnancy knowing our baby is unaffected'. To try to make that wish come true through PGD is very much in accord with the goal of "helping those families at genetic disadvantage reproduce as normally as possible', in the sense that the wanted pregnancy begins with optimism. Incidentally, that same day in 1986 saw the publication of a report in which the newly developed technique of polymerase chain reaction (PCR) permitted DNA analysis on as little as 75 cells. ${ }^{12}$ The barrier to developing PGD had, until that time, been the lack of sensitivity of the genetic analysis. It was clear, from that moment on, that the technology was going to be capable of serving the aspirations of many families threatened by genetic disease, namely, to exclude a specific genetic risk from the start; to fulfil the wish 'to start a pregnancy knowing our baby is unaffected'.

The principal benefit of PGD compared with other forms of prenatal diagnosis (PND) is the avoidance of selective abortion. M ore particularly it is the avoidance of the terrible burden of having to choose between a high chance of giving birth to an affected child and terminating a wanted pregnancy, in that $25-50 \%$ of situations, where the baby is shown to be affected. It is not only the agonising decision that is avoided, but the well-known psychological sequelae following termination for fetal abnormality, such as the guilt and the pain of coping with the period when the baby would have been due. ${ }^{13}$ Furthermore, all women embarking on a high risk pregnancy and planned PND suffer the long wait for the prenatal test and the result - a period sometimes called the 'tentative pregnancy' when they dare not believe they are going to have a baby. This, too, is circumvented by PGD. However, it has to be recognised that in its place is the worrying uncertainty of establishing a pregnancy by IVF and the repeated disappointments that can often arise.

PGD offers particular opportunities to four groups of couples:

- Where a woman with a known genetic risk has had a tubal ligation because (acceptable) prenatal diagnosis was not available at the time;

- Where a woman is having IVF for infertility reasons and also happens to face a high genetic risk;

- Where a woman with a known genetic risk has had a disastrous reproductive history with repeated selective abortions following prenatal diagnosis; 
- Where a woman with a known genetic risk has an absolute objection to abortion on moral and religious grounds.

Increasingly the requests for PGD come from women who do not wish to contemplate an abortion, but dare not start a pregnancy because of their high genetic risk. In these circumstances, discussion of the reliability of PGD becomes a key part of the counselling. Would they wish to have a more reliable confirmatory prenatal test later in pregnancy or not? How would they cope with the small residual risk of an affected child due to a misdiagnosis at PGD?

At the present time, IVF and PGD are major undertakings in terms of ovarian stimulation by drugs, the monitoring of follicle growth and egg maturation, egg collection and eventual embryo transfer. It is not clear how much this, and the personal financial cost in many cases, will deter couples from choosing PGD. Increasingly, in the future, at-risk couples could weigh up the disadvantages of the medicalisation and complications of assisted conception and any residual uncertainties about the accuracy and long-term safety of the PGD procedure, and balance these against the frightening prospect of an abortion following PND, regardless of their moral position on abortion per se. The extent to which this could happen depends, on the one hand, on technical advances in IV F, embryo biopsy and single cell genetic analysis and, on the other, the opportunities offered to couples facing high genetic risk. The technological advances will happen for sure (although not necessarily the funding needed for such services) and, judging by requests for information about PGD from people attending genetic clinics, there will be a demand. The main determining factor is likely to be the priority afforded to the development of PGD within medical services. In the forthcoming debate on the development or not of PGD services it will be important that its potential place within the overall genetic services is understood by policy makers. The current state of the country's overall genetic services will also be an important consideration, and there is significant variation throughout Europe, as documented in the recent report from the Concerted $A$ ction on $\mathrm{G}$ enetic Services in $\mathrm{E}$ urope. ${ }^{14} \mathrm{~A} s$ with the introduction of any new medical service, the cost will have to be justified within the limits of the health care budget. There will be competing claims. In this debate on fair allocation (distributive justice), I just ask that the appropriate goals of medical genetic services are used in any cost-benefit analyses.

\section{The Impact of Genetic Testing of Offspring Being Separated from Pregnancy and Therefore The Prospect of Abortion}

A s we have seen, the opportunity to avoid termination of pregnancy after prenatal diagnosis will greatly enhance the options available to those at risk of transmitting a serious genetic disorder to their offspring. But what of the general effect of a move from prenatal diagnosis and selective termination of an established pregnancy to preimplantation genetic diagnosis and selective transfer of unaffected embryos to the uterus? The relationship between the woman and her conceptus is made more remote or 'emotionally distant' by the use of IVF and is of a different degree (and possibly of a different kind) than the prenatal relationship between a woman, or should one say mother, and her fetus. A s implantation follows conception, and the fetus grows and starts to move as pregnancy progresses, so there is a greater parental investment of love and (most women would feel) a greater moral obligation to their fetus. This change is reflected in a major shift in the balance between selection and treatment as a medical intervention. With the preimplantation embryo the presumption is in favour of selection, and this is certainly so where genetic disease is concerned, with embryo gene therapy outlawed in Britain. Furthermore, there is likely to be great reluctance on the part of the health professionals performing PG D to transfer an affected embryo, should the couple suddenly change their view and wish to put their faith in postnatal treatment. By the time of the birth, however, the presumption is in favour of treatment, although withholding treatment in the neonate can be justified in some circumstances.

Given the relative emphasis on selection in the preimplantation period, and the widely perceived lesser moral obligation to the early in vitro embryo compared to the 12-week fetus, could there be pressure to use $P G D$ for more trivial reasons than the avoidance of transmitting serious genetic disease? D oes the prospect of a traumatic abortion act as a break on those who might otherwise request prenatal diagnosis for fetal sex, for example? What about requests for PGD solely for sex selection? The licensed use of PGD can be regulated so as to preclude its use in this way. What might be more problematic is the question of incidental selection by sex when PGD is being performed for other legitimate reasons. In verifying the normal 
chromosomal status of embryos to be transferred (with the remainder to be frozen) as part of a medical indication for PGD, the doctor could well be faced with knowing the sex of, say, four embryos, and also what the couple's preference would be. It may not be possible to regulate effectively what is to be done in these circumstances. However, leaving the decision to the conscience of the doctor or professional guidelines is unlikely to undermine the fabric of society.

\section{Eugenic Abuse and Lists of What is Serious Enough to Qualify for PGD}

It is not rare to hear the view that making PGD and embryo selection easier will encourage a subtle form of eugenic abuse, in which there will be social and economic pressure to avoid children with less and less severe genetic conditions, coupled with less respect for people with disabilities or a reduction in social spending on facilities and assistance for them. With regard to the latter point, there is no direct evidence that the rise in genetic testing and the offer of prenatal diagnosis and selective abortion have led to a general increase in discrimination against disabled people or a loss of facilities. If anything, the trend has been in the opposite direction. Concern has also been expressed that individuals with disorders that could be 'prevented' by PGD or termination of pregnancy will feel undervalued and less tolerated by society. But it is important to emphasise that wanting a child to be free from disability (which is a reasonable desire) is not necessarily to value disabled people less as persons..$^{15}$ This is repeatedly demonstrated by loving parents, who are so caring of their disabled child and of whose achievement they are very proud, and yet they seek PND to avoid a further similarly affected child.

Chadwick ${ }^{16}$ reminds us that it is not only handicapped fetuses that are aborted. Thousands of healthy fetuses are also aborted every year if they constitute a threat to the health or welfare of the mother, but this does not inevitably lead to the view that those who are a threat to someone's health or welfare are less valuable or less worthy of respect. She suggests that the important boundary is that between fetus and adult, not between handicapped and healthy, and as long as we maintain the boundary, there is little reason to think that abortion for fetal handicap or avoidance by PGD will lead to less respect for those handicapped people who are alive. N evertheless, we also cannot afford to be complacent and society must strive both to raise awareness of disability issues and improve the services to disabled people, so that they can enjoy the same freedoms, free from discrimination, that people without a disability enjoy.

A s regards social and economic pressure on families with genetic disease to opt for PGD or PND, there has rightly been concern to ensure confidentiality of genetic data and no genetic discrimination in terms of access to health care. This is particularly important where health care is provided through health insurance schemes.

A Il the above issues are general ones relevant to existing genetic testing and prenatal diagnosis and, whilst they demand constant vigilance, an increase in the availability of PGD is unlikely to undermine the efforts to protect against genetic discrimination.

O ne suggestion that keeps cropping up is that there should be a list of conditions for which prenatal diagnosis and selective abortion is allowed. A $n$ extension of this concept would be a list (the same or modified) for conditions that justify PGD. Those who propose there should be a list of conditions for which prenatal diagnosis is allowed clearly have little appreciation of the limitations of disease delineation. $\mathrm{N}$ ot only are there several thousand recognised genetic disorders, but many show a wide variation in severity that is not clearly predicted by the prenatal test. Furthermore, the seriousness with which a disease is viewed is dependent also on the success of the treatment available. Imagine drug companies lobbying for a disease to come off the list because they claim it is now treatable with their products; or people lobbying for a disease to go on the list because they claim they no longer have access to (free) treatment. In the $O$ pinion on The $E$ thical $A$ spects of $P$ renatal $D$ iagnosis ${ }^{17}$ from the Group of Advisers on the Ethical Implications of Biotechnology of the European Commission, it states

'The on-going ethical debate, the scientific progress which is rapidly enlarging the medical scope of PND, the variability of many genetic diseases and fetal anomalies in their expression, severity or prognosis render inappropriate the listing of illnesses or handicaps that qualify for PND'.

'A framework, based on general ethical principles, is preferable to determine which PND and associated genetic counselling will be offered to women and couples. In this context, a "case-by-case" approach would have the advantage of minimizing reference explicitly to a model of normality, which would lead to stigmatization'. 
What is true of PND generally would also be true of PGD. Furthermore, there is no agreement on what constitutes a 'serious disorder', a term that often appears in policy discussions. Wertz et $\mathrm{al}^{18}$ report on questionnaire responses from 1481 members of organisations in the USA, Canada and Europe associated with medical genetics. There was a spectacular lack of consensus! The majority of US geneticists (52\%) thought professional associations should not develop lists of serious disorders.

There are no short cuts. Families considering PGD need one-to-one counselling by properly trained staff to help them make an informed decision that is right for them.

\section{The Role of Counselling}

It comes as no surprise to me that there is no clear consensus on what is a 'serious disorder', especially when considered in the context of what might justify selective abortion or inclusion in a PGD programme. Weighing up risks and coming to a reproductive decision is a complicated and individual matter. Risk consists of at least two components - chance or probability, and the extent of damage or burden. $B$ urden itself derives from both the degree of pressure or load, and the ability to cope with it. A $n$ assessment of the burden comes from a dialogue between the genetic counsellor and the couple who bring their own subjective experience to it. The counselling process is not only supportive for the family involved, but constitutes the best practical solution to discovering what is 'serious' in an individual case.

The way forward is not lists, but counselling and support in coming to an informed decision. O ne of the concerns with prenatal screening, where the increased chance that the baby has a genetic disorder is only discovered during pregnancy, is that there may not be time for the couple to come to a fully informed decision. $\mathrm{G}$ reat care has to be taken to ensure adequate counselling, and that the relentless progression of the pregnancy does not force a hasty decision. With PGD, initial counselling is by definition preconceptional, and reproductive decisions become part of planned parenthood by the couple, where both take some responsibility. Even when PGD becomes an established service offered to couples facing high genetic risks, it will never become 'routine' in the sense that those involved will be unthinking about what they are doing. Thus, whilst there is an urgent need to improve the level of counselling associated with the offer of prenatal screening tests (largely by appropriate training courses for midwives and other health professionals), the development of PGD per se will not undermine responsible reproductive decision making by couples. $R$ ather it will tend to enhance it.

\section{The Way Forward}

This paper has focused on the ethical framework within which PGD, as an additional PND option, will develop, and not the practicalities of the actual service development. It is often claimed that our ability to deal with the ethical implications of new technologies lags far behind the technical 'know-how'. In the light of this review, this does not seem to be the case for PGD provided it is included in genetic counselling and prenatal diagnosis services as a whole for which we have many years of experience. There are no major ethical dilemmas associated with PGD that are not already understood fairly well in the context of PND generally. In their carefully considered $O$ pinion on The $E$ thical $A$ spects of Prenatal Diagnosis, ${ }^{17}$ the Group of A dvisers on the $E$ thical I mplications of B iotechnology of the E uropean Commission chose to exclude consideration of PGD because it 'raises additional ethical questions which the $G$ roup intends to study at a later stage'. H owever, the Group was able to establish a broad consensus on practical recommendations and an ethical framework which would, in my opinion, serve PGD very well. O ne particular recommendation (para 2-7) is of central importance. PND - and I would include PGD - 'should always be considered as a medical act and be offered on the basis of specific medical indications. The choice of sex or other characteristics for non-medical reasons is an ethically unacceptable indication for PND and should be prohibited'. I believe that the interests of couples who might need PGD are protected by the fact that it is a medical act. This is not just because of the need to maintain technical standards, where invasive clinical interventions and drug therapy are concerned, but also because of the benefits that come from that broad clinical responsibility we call 'the professional duty of care'. This duty of care must be informed by clear goals that marry the interests of both society and individual families and I would argue that these are emerging. Restoration of reproductive confidence, to the point where couples facing serious genetic risks have the prospect of healthy children without recourse to abortion, is an important new option that is in line with 
the emerging consensus on the goal of medical genetic services.

It is important to recognise the distinction between our ability to deal with the ethical implications and whether the recommended services, counselling and ethical safeguards are actually in place. There is a great deal to be done in training health professionals in genetic counselling and in the development of clinical genetic services generally.

PGD is in its infancy, and clinical trials should ideally be confined to just a few centres until there are more data on reliability and safety. There are good grounds for establishing an international registry to organise this follow-up worldwide. The recent data from the International Working Group on Preimplantation $G$ enetics reports that, worldwide, 72 unaffected babies have been born following cleavage stage PGD for $X$-linked disorders, single gene defects, or inherited chromosomal translocations. It is believed that there have been three misdiagnoses, two detected on confirmatory prenatal diagnosis ${ }^{19}$ [and J oyce $\mathrm{H}$ arper, personal communication]. Combining all forms of PGD, including tests for age-related aneuploidy, over 1000 cycles to biopsy have been performed.

In parallel with carefully regulated research and clinical trials, there is a need for more professional and public awareness of PGD, including non-technical literature such as the Progress Guide to Preimplantation Diagnosis. ${ }^{20}$ In the next century families threatened by recurrent genetic risks will be grateful indeed that the professionals involved had the courage to proceed with the development of PGD.

\section{Acknowledgements}

In developing these ideas, I have been influenced by many people, particularly D r B ernadette M odell and D r Elizabeth A nionwu, and al so D r Sonia le B ris and $\mathrm{M} \mathrm{s} H$ enrietta Wallace with whom I shared the opportunity to contribute to the deliberations on PND of the E uropean Commission's G roup of A dvisors on the Ethical Implications of Biotechnology between 1994 and 1996.

\section{References}

1 Tizzard J: B ritain leads the way in E urope (A report of the Council of Europe's Third Symposium on Bioethics). Progress in Reproduction 1997; 1: 10-11.

2 U nited Nations: Family building by fate or design. U nited $\mathrm{N}$ ations D epartment of $\mathrm{E}$ conomic and Social A ffairs, N ew York, 1987.
3 Carter CO, Fraser Roberts JA, Evans KA, Buck AR: Genetic clinic: a follow-up. $L$ ancet 1971; Feb 6: 281-285.

4 Modell B, Ward RHT, Fairweather DVI: E ffect of introducing antenatal diagnosis on reproductive behaviour of families at risk for thalassaemia major. BMJ 1980; 280: 1347-1350.

5 Pembrey M E : Prenatal diagnosis: healthier, wealthier and wiser? In: R oy DJ, Wynne BE, O Id RW, (eds). Bioscience Society. Report of the Schering Workshop on Bioscience Society, B erlin 1990. John Wiley and Sons, Chichester, 1991, pp53-66.

6 Carter CO: Recent advances in genetic counselling. Nursing Times 1979; 75: 1795-1798.

7 Murray J, Cuckle H, Taylor G, Hewison J : Screening for fragile $X$ syndrome: information needs for health planners $J$ M ed Screening 1997; 4: 60-94.

8 A ndrews LB, Fullarton JE, H oltzman NA, M otulsky A G (eds).: A ssessing $\mathrm{G}$ enetic Risks. Implications for $\mathrm{H}$ ealth and Social Policy. Committee on A ssessing R isks, Institute of Medicine. National A cademy Press, Washington DC, 1994.

9 M odell B and Kuliev A M : Services for thalassaemia as a model for cost-benefit analysis of genetic services. J I nherit M etab D is 1991; 14: 640-651.

10 Pembrey ME and A nionwu E N : E thical aspects of genetic screening and diagnosis. In: Rimoin DL, Connor JM, Pyeritz RE, (eds). Emery and Rimoin's Principles and Practice of Medical Genetics, 3rd edn Churchill Livingstone, N ew York, 1996.

11 World Health Organization: Community approaches to the control of hereditary diseases. U npublished document HD/W G/85.10. WH O, G eneva, 1985.

12 Saiki R K et al: A nalysis of enzymatically amplified betaglobin and HLA-DQ alpha DNA with allele-specific oligonucleotide probes. Nature 1986; 324: 163-168.

13 White-van Mourick MCA, Connor J M, Ferguson-Smith MA: The psychosocial sequelae of a second-trimester termination of pregnancy for fetal abnormality for fetal abnormality. Prenat Diagn 1992; 12: 189-204.

14 Concerted A ction on G enetic Services in E urope 1997.

$15 \mathrm{H}$ arris J: Wonderwoman and Superman. Oxford U niversity Press, Oxford, 1992.

16 Chadwick RF: The perfect baby: introduction. In: Chadwick R F, (ed). E thics, Reproduction and Genetic Control. R outledge, L ondon, 1992.

17 European Commission: The E thical A spects of Prenatal Diagnosis. Opinion of the Group of Advisers on the E thical Implications of Biotechnology, B russels, 1996.

18 Wertz DC, Knoppers BM, Chadwick R, Penchaszadeh $V B$.: What is a 'serious' genetic disorder? R esults of a geneticist survey. A bstract. B razilian Journal of $G$ enetics 1996; 19 no. 2 supplement: 264.

$19 \mathrm{H}$ arper J: Preimplantation diagnosis of inherited disease by embryo biopsy. A $n$ update of the world figures. J A ssist Repro G enet 1996; 13: 90-95.

20 Furedi $A$ : The Progress $G$ uide to Preimplantation Diagnosis. A Progress Educational Trust Publication, London 1996. 